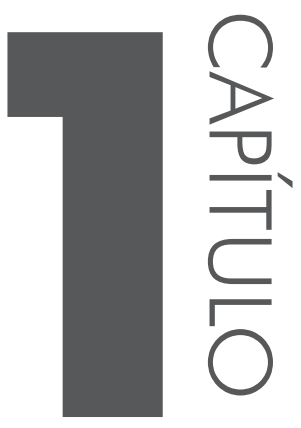

\title{
USO DE DIFERENTES MÉTODOS PARA A OBTENÇÃO DO EXTRATO DE SOJA E OKARA
}

Dafne Garcia Pereira Neusa Fátima Seibel

\section{INTRODUC̣ÃO}

É crescente a preocupação por parte da população em consumir alimentos saudáveis, e pesquisas recentes têm mostrado a importância desse novo segmento no mercado. Por outro lado, as indústrias têm desenvolvido novos produtos a partir de alternativas que podem ser consideradas como resíduos industriais, as quais, se usadas em substituição a outros ingredientes, proporcionam aos alimentos alto valor nutricional, com características desejáveis, além de gerar valor agregado.

$\mathrm{Na}$ composição da soja, há importantes componentes, sendo que os de maior destaque são as proteínas, as isoflavonas, os fosfolipídios, os antioxidantes, as vitaminas e as fibras, os quais têm comprovada ação benéfica para a saúde huma- 
na. O consumo de soja ou de produtos à base de soja na dieta humana contribui para uma melhoria na qualidade de vida por reduzir riscos de doenças crônicas não transmissíveis, alguns tipos de câncer e reduzir o colesterol (BOWLES; DEMIATE, 2006).

Além do mais, a soja apresenta uma boa qualidade nutricional e é rica em aminoácidos variados, sendo deficiente em apenas dois aminoácidos sulfurados, que são a metionina e a cistina (TASHIMA; CARDELLO, 2003). Mesmo com todos esses benefícios, esse grão é pouco consumido no Brasil devido ao sabor característico, o qual não é bem aceito. Em países orientais, por sua vez, a soja e seus derivados são muito utilizados na alimentação como fonte proteica.

O extrato de soja (ES) é considerado um dos seus derivados mais conhecidos. Obtido a partir da extração aquosa da soja, é ideal para substituir o leite, especialmente na alimentação de indivíduos que tenham intolerância ou restrição à lactose, sendo também indicado em dietas com ingestão de colesterol reduzido. O okara, que é o resíduo do processamento do ES, tem todas as propriedades da soja e grande potencial para a utilização nos alimentos, porém ainda é pouco utilizado nas indústrias alimentícias. Durante a produção do extrato de soja, somente $3 \%$ a $5 \%$ da matéria seca é retida no ES, ou seja, aproximadamente $95 \%$ dos sólidos do grão de soja ficam no okara. Com isso, pode-se afirmar que as maiores porcentagens de nutrientes da soja passam para o okara, o que é um indicativo do alto valor nutritivo do mesmo (PERUSSELLO, 2008).

Segundo Bowles e Demiate (2006), a Food and Drug Administration (FDA) publicou, nos Estados Unidos, ainda em 1999, um documento ressaltando as ações benéficas da soja e autorizando indústrias a colocarem em seus rótulos as propriedades do consumo de soja. Com isso, origina-se também a importância de se estudar seus derivados como o ES e o okara, já que ambos têm potencial para a aplicação em diversos tipos de produtos e têm as propriedades dos grãos de soja. Dessa forma, esta pesquisa teve por objetivo elaborar extrato de soja (ES) e okara por diferentes métodos e comparar os produtos obtidos para futuras aplicações em alimentos.

\section{SOJA}

A soja (Glycine $\max$ (L.) Merril) é uma leguminosa já conhecida pelos chineses há cerca de cinco mil anos, que passou a ser cultivada nos Estados Unidos apenas no século XX. Os Estados Unidos são o maior produtor de soja, seguido pelo Brasil, Argentina e China. Juntos, esses quatro países são responsáveis por $90 \%$ da produção mundial (CALLOU, 2009). Nas últimas décadas, a produção de soja no mundo é uma das atividades econômicas que mais cresceu; isso se deve ao desenvolvimento e estruturação de um sólido mercado da soja no Brasil 
e internacionalmente, por ser uma importante fonte de proteína vegetal e pela geração de novas tecnologias para a exploração dos grãos de soja (HIRAKURI; LAZZAROTTO; 2010).

A composição química da soja apresenta componentes importantes como: proteínas, carboidratos, lipídios, minerais e vitaminas. Destacam-se as proteínas da soja, que entre esses nutrientes do reino vegetal é a que têm um melhor balanço de aminoácidos essenciais e qualidade comparável às proteínas de origem animal (PEREIRA et al. 2009). O consumo da soja tem aumentado consideravelmente no mundo todo, resultado das suas propriedades funcionais e de seus benefícios, sendo altamente recomendável a sua inclusão, assim como também a de seus derivados, na dieta diária dos consumidores (JÚNIOR et al., 2006). No Brasil, o consumo de grãos de soja está fortemente associado à manutenção da boa saúde e à redução do risco de doenças crônicas, principalmente devido a isoflavonas, por possuírem propriedades biológicas benéficas (FANTE et al. 2011).

Behrens e da Silva (2004) fizeram uma pesquisa sobre a atitude dos consumidores em relação à soja e seus derivados e concluíram que o consumo desses alimentos ainda é baixo, sendo que, dentre os produtos derivados de soja, as proteínas, o ES e o tofu foram reconhecidos pelos consumidores como mais conhecidos e consumidos. Já iogurte e soja em grãos são os menos consumidos. Essa mesma pesquisa mostra ainda que os consumidores reconhecem a importância do valor nutricional da soja e seus derivados, mas não sabiam de todos os benefícios do consumo regular de produtos derivados da soja.

\subsection{Métodos de produção de extrato de soja e okara}

Segundo Moreira et al. (2010), a obtenção do extrato de soja se baseia na seleção e lavagem dos grãos, seguidas de aquecimento, resfriamento e retirada das cascas, e após esses procedimentos é realizado um novo aquecimento, trituração e filtragem da massa de grãos. No trabalho de da Cunha et al. (2007), foram utilizados $350 \mathrm{~g}$ de soja e 4,5 1 de água para a obtenção de okara. Os grãos foram fervidos com 1,5 1 de água por cinco minutos, em seguida essa água de cozimento foi descartada. Os grãos foram lavados cuidadosamente em água corrente e submetidos a cozimento por cinco minutos em 31 de água em ebulição. Foram resfriados em repouso até $40{ }^{\circ} \mathrm{C}$ e triturados em liquidificador doméstico por três minutos. Após, foram colocados em panela aberta, para cozinhar por dez minutos sob constante homogeneização. A massa (okara) foi filtrada em pano de algodão, seca em estufa a $180^{\circ} \mathrm{C}$ e triturada em liquidificador doméstico na velocidade máxima por cinco minutos.

Zadinello et al. (2010) utilizaram três metodologias diferentes para a obtenção do ES, utilizando $300 \mathrm{~g}$ de grãos de soja em cada processo. Na primeira 
metodologia, os grãos foram submetidos à maceração por $6 \mathrm{~h}$, utilizando $900 \mathrm{ml}$ de água; após, foram lavados e, em seguida, foram triturados em liquidificador com 11 de água por cinco minutos e filtrados em coador de flanela. Após, foi adicionado 1,8 1 de água, $140 \mathrm{~g}$ de açúcar, $1,6 \mathrm{~g}$ de sal e $2 \mathrm{~g}$ de bicarbonato de sódio, e tudo foi triturado em liquidificador para misturar os ingredientes por cinco minutos, com rendimento de três litros.

$\mathrm{Na}$ segunda metodologia, a soja foi levada à ebulição por cinco minutos com 1,5 1 de água e $1 \mathrm{~g}$ de bicarbonato de sódio. Os grãos foram lavados e esfregados manualmente para retirada das cascas. A soja foi fervida com 11 de água e $1 \mathrm{~g}$ de bicarbonato de sódio por mais cinco minutos; depois de amornados, os grãos foram triturados em liquidificador por três minutos, e em seguida foram colocados para cozinhar em recipiente aberto por dez minutos e coados em pano de algodão. Em seguida, o extrato foi fervido por dois minutos e foram adicionados $140 \mathrm{~g}$ de açúcar e 1,6 g de sal. O rendimento final nessa metodologia foi de dois litros (ZADINELLO et al., 2010).

E no terceiro método, os grãos de soja foram submetidos ao aquecimento em potência máxima, por três minutos e vinte segundos, em forno de micro-ondas. Foram utilizados $900 \mathrm{ml}$ de água para a maceração em banho-maria por 1 hora, e essa água foi descartada. Após, os grãos foram homogeneizados em liquidificador por cinco minutos com 2,1 1 de água e coados em coador de flanela. Novamente foram colocados $140 \mathrm{~g}$ de açúcar e 1,6 g de sal, e o rendimento também foi de 2 litros de extrato (ZADINELLO et al., 2010).

Caus et al. (2008) utilizaram a seguinte metodologia para obtenção do extrato de soja: os grãos foram selecionados e levados a cozimento durante cinco minutos; em seguida foram realizadas drenagem e lavagem em água fria; os grãos foram novamente levados a cozimento durante cinco minutos na proporção 1:3; após esse procedimento, os grãos foram triturados por três minutos e cozidos por mais dez minutos; em seguida foram filtrados e cozidos por mais dois minutos, de modo a se obter o extrato de soja.

\subsection{Aplicações do extrato de soja e okara}

O ES possui aspecto parecido com o leite de vaca, quando preparado em condições adequadas, e tem alto valor nutritivo. Pode ser comercializado de várias formas, com adição ou não de aromatizantes; na forma “original”, pode ser combinado com frutas diversas, produção de tofu, iogurte à base de soja, entre outros (BRANCO et al., 2007).

Segundo Maia, Rossi e de Carvalho (2006), o padrão de qualidade para o extrato de soja é umidade de até 93\%, 3\% no mínimo de proteínas, mínimo de $1 \%$ de lipídios, 2,8\% no máximo de carboidratos e cinzas de $0,6 \%$ no máximo. 
O produto deve ser obtido a partir da emulsão aquosa resultante da hidratação dos grãos de soja, seguido do processamento tecnológico que pode ser variado, adicionado ou não de ingredientes opcionais.

$\mathrm{Na}$ pesquisa realizada por Uliana e Filho (2010), foi produzida uma bebida mista de extrato de soja e suco de amora, com o objetivo de caracterizar energeticamente bebidas preparadas a partir de diferentes concentrações de ES e suco de amora e diferentes concentrações de sólidos solúveis. Os valores energéticos variaram entre 41,60 a 60,50 kcal/100 g-1. Casé et al. (2005) elaboraram um produto similar ao leite, com o ES enriquecido com cálcio, com o objetivo de melhorar as qualidades nutricionais do ES, já que este apresenta baixo conteúdo de cálcio. Kempka et al. (2008) elaboraram uma bebida láctea fermentada sabor pêssego utilizando soro de queijo e ES como substratos.

Segundo Larosa et al. (2006), com o processamento de $1 \mathrm{~kg}$ do grão de soja, obtém-se de 6 a 9 litros de ES, e cerca de 700 g do subproduto okara. Já Cantuária et al. (2008) citam em seu trabalho que, em média, cada $1 \mathrm{~kg}$ de soja em grãos gera $613 \mathrm{~g}$ de okara seco. O okara é obtido como resíduo do processamento do ES, tem baixo valor de mercado, alto valor nutritivo, é rico em proteínas, com ótimo perfil de aminoácidos essenciais e alta digestibilidade in vitro. Mesmo com todas essas qualidades nutricionais, o okara, na maioria das vezes, é utilizado na formulação de ração animal (DANELUZ; DA CUNHA, 2009).

O okara pode ser aplicado em áreas como panificação, na produção de pães, biscoitos e bolos, e em produtos cárneos, sendo uma alternativa saudável e de baixo custo para aumentar o rendimento dos alimentos e também sua qualidade nutricional (LAROSA et al., 2006). O okara foi utilizado no trabalho de Madrona e Almeida (2008) que testaram diferentes proporções de okara na produção de um biscoito doce. O okara também foi utilizado na produção de pães do tipo francês no trabalho de Bowles e Demiate (2006). Na literatura, também foi encontrada a utilização de okara na produção de pães de queijo (APLEVICZ; DEMIATE, 2007) e na produção de hambúrgueres à base de okara, no trabalho de dos Santos, Miguel e Lobato (2010).

\section{MATERIAIS E MÉTODOS}

Os grãos de soja que foram utilizados para a obtenção do extrato de soja e okara são da variedade BRS 257, fornecidos pela Embrapa Soja (Empresa Brasileira de Pesquisa Agropecuária).

\subsection{Obtenção do extrato de soja e do okara}

O extrato de soja e okara foram obtidos baseados na metodologia de Mandarino, Benassi e Carrão-Panizzi (2003) com algumas alterações. Consistiu em 
adicionar os grãos de soja em água na proporção de 1:5 (grão: água) e deixar ferver por cinco minutos. Essa água de fervura foi descartada, e os grãos, lavados em água corrente. Em seguida, foram colocados em água fervente nas proporções de 1:4, 1:6, 1:8 e 1:10 por cinco minutos. Depois de resfriar a água juntamente com os grãos até a temperatura ambiente, estes foram triturados por um minuto em liquidificador industrial (Metvisa LQ15). A massa obtida foi peneirada para separar o ES do okara úmido. Após, foi centrifugada, e o mesmo procedimento foi repetido, porém sem a centrifugação. O okara úmido foi desidratado em estufa com circulação de ar a $60^{\circ} \mathrm{C}$.

\subsection{Composição proximal}

A determinação de umidade, cinzas, lipídios e proteínas (fator de correção 6,25 ) foi realizada segundo as metodologias descritas pela AOAC (Association of Official Analytical Chemists) (ASSOCIATION OF ANALYTICAL COMMUNITIES, 1995). Os carboidratos foram calculados por diferença [100-(umidade+cin zas+lipídios+proteínas)].

\subsection{Sólidos solúveis}

O teor de sólidos solúveis das amostras de ES foi determinado através do método descrito pelo Instituto Adolfo Lutz (INSTITUTO ADOLFO LUTZ, 2008).

\subsection{Determinação da cor}

A cor das amostras de ES foi avaliada em colorímetro Konica Minolta CR400, e os resultados obtidos foram expressos em valores de a* que variam do verde ao vermelho, e em valores de $b^{*}$ que variam do azul ao amarelo.

\subsection{Determinação de isoflavonas}

As isoflavonas dos extratos de soja e dos grãos de soja foram determinadas segundo Berhow (2002) e Carrão-Panizzi, Favoni e Kikuchi (2002). Para a extração, foram pesados $100 \mathrm{mg}$ da amostra, transferindo-a para tubo tipo Falcon. Adicionaram-se $4 \mathrm{ml}$ de etanol acidificado com ácido acético e agitaram-se os tubos (cinco segundos) a cada quinze minutos durante uma hora, em agitador vórtex. Em seguida, transferiram-se os tubos para o banho ultrassônico, a fim de reduzir bolhas e auxiliar na extração. O sobrenadante foi repassado para microtubos tipo Eppendorf e centrifugado a 14.000 g sob refrigeração a $4{ }^{\circ} \mathrm{C}$, durante quinze minutos. Em seguida, filtrou-se o sobrenadante com seringa de vidro acoplada a membrana filtrante de $0,45 \mu \mathrm{m}$, coletando o filtrado em microtubos tipo 
vial. Tampou-se com septa e organizaram-se os microtubos tipo vial no carrossel para injeção.

As amostras foram analisadas em cromatógrafo líquido equipado com coluna de fase reversa YMC-Pack ODS-AM (C-18) S-5 $\mu \mathrm{m}$, diâmetro $250 \times 4,6$ mm, autoinjetor de amostras, bomba binária e detector de arranjo de fotodiodos. A corrida cromatográfica por gradiente de eluição foi programada e regulada para o fluxo de 1,0 ml/minuto. Após a corrida, é visualizado o cromatograma e os 11 espectros de absorbância correspondentes a cada amostra. De posse dos espectros padrão das isoflavonas baseado em Carrão-Panizzi, Favoni e Kikuchi (2002), obtidos previamente durante calibração, os tempos de retenção e as faixas de absorbância foram comparados para a identificação dos picos de interesse. A integração manual dos picos identificados nas amostras, assim como os valores das áreas integradas de cada pico, massas iniciais, volume de extração e de injeção, utilizando os fatores de calibração, foi convertida em teores das isoflavonas.

\subsection{Propriedades tecnológicas}

As análises de propriedades tecnológicas volume de intumescimento (VI), índice de absorção de água (IAA), índice de absorção de óleo (IAO) e densidade foram feitas para as amostras dos grãos de soja e dos okaras segundo os métodos descritos por Seibel e Beléia (2009).

\subsection{Tratamento estatístico}

Os dados da composição proximal, propriedades tecnológicas, análise de cor e sólidos solúveis foram analisados estatisticamente pelo software Statistica 10.0, utilizando análise de variância (Anova), e a diferença entre as médias foi comparada pelo teste de Tukey ao nível de $5 \%$ de significância.

\section{RESULTADOS E DISCUSSÃO}

Os grãos de soja utilizados para as extrações são ricos em proteínas, contendo aproximadamente $42 \mathrm{~g} / 100 \mathrm{~g}$ em sua composição, e possuem baixo teor de lipídios, $19 \mathrm{~g} / 100 \mathrm{~g}$ (Tabela 1.1). Esses resultados comprovam a boa qualidade nutricional da soja, por conter em sua composição a maior porcentagem em proteínas e baixa porcentagem de lipídios. Barbosa (2007) obteve para os grãos de soja os seguintes resultados: umidade 5,07 g/100 g, cinzas 5,48 g/100 g, proteínas 35,16 g/100 g e lipídios 20,01 g/100 g. Resultados similares foram encontrados neste trabalho com relação ao teor de cinzas $(5,39 \mathrm{~g} / 100 \mathrm{~g})$ e lipídios $(19,05 \mathrm{~g} / 100$ g). Porém, umidade $(11,03 \mathrm{~g} / 100 \mathrm{~g})$ e proteínas $(41,91 \mathrm{~g} / 100 \mathrm{~g})$, neste trabalho, foram superiores. 
Tabela 1.1 Composição proximal dos grãos de soja $(\mathrm{g} / 100 \mathrm{~g})$

\begin{tabular}{cc}
\hline Análises & Grãos de soja \\
\hline Umidade & $11,03 \pm 0,25$ \\
Proteínas & $41,91 \pm 0,76$ \\
Cinzas & $5,39 \pm 0,07$ \\
Lipídios & $19,05 \pm 0,65$ \\
Carboidratos* $^{*}$ & 22,62 \\
\hline
\end{tabular}

Média \pm desvio padrão.

*Carboidratos foram calculados por diferença.

Os grãos também apresentam boas características tecnológicas por absorver grande quantidade de água (VI 8,00 ml/g e IAA 3,25 g/g), sendo que, na formulação de alguns produtos, essa propriedade de hidratação dará maior rendimento (Tabela 1.2). Segundo Seibel e Beléia (2009), essas propriedades tecnológicas são importantes, pois alteram as características nutritivas e sensoriais no produto final e também em sua preparação, processamento e estocagem.

Tabela 1.2 Análises tecnológicas dos grãos de soja

\begin{tabular}{cc}
\hline Análises & Grãos de soja \\
\hline Volume de intumescimento $(\mathrm{ml} / \mathrm{g})$ & $8,00 \pm 1,00$ \\
Índice de absorção de água $(\mathrm{g} / \mathrm{g})$ & $3,25 \pm 0,20$ \\
Índice de absorção de óleo $(\mathrm{g} / \mathrm{g})$ & $2,89 \pm 0,18$ \\
\hline
\end{tabular}

Média \pm desvio padrão.

O maior conteúdo de isoflavonas (Tabela 1.3) nesses grãos de soja foram nas formas G-Daidzina (59,37 mg/100 g), G-Genistina (54,71 mg/100 g), M-Daidzina $(56,39 \mathrm{mg} / 100 \mathrm{~g})$ e M-Genistina (93,43 mg/100 g). Pelas análises, pode-se observar que a soja não possui isoflavonas na forma acetil, e o total de isoflavonas nesses grãos de soja foi de 305,40 mg/100 g.

As isoflavonas estão presentes em grande concentração na soja e são associadas a ações benéficas para o organismo, como redução dos sintomas da menopausa, por serem consideradas como fitoestrógenos. As isoflavonas também são anticancerígenas e antioxidantes, e contribuem para a redução do LDL-colesterol (Low Density Lipoproteins). As principais formas de isoflavonas encontradas na soja são a genisteína, a daidzeína e gliciteína, sob a forma de agliconas (SEIBEL et al., 2013). 
Tabela 1.3 Isoflavonas dos grãos de soja $(\mathrm{mg} / 100 \mathrm{~g})$

\begin{tabular}{cc}
\hline Isoflavonas & Grão de soja \\
\hline G-Daidzeína & $59,37 \pm 0,61$ \\
G-Gliciteína & $11,86 \pm 0,57$ \\
G-Genisteína & $54,71 \pm 0,42$ \\
M- Daidzeína & $56,39 \pm 0,37$ \\
M- Gliciteína & $14,40 \pm 0,15$ \\
M- Genisteína & $93,49 \pm 1,32$ \\
A- Daidzeína & - \\
A- Gliciteína & - \\
A- Genisteína & - \\
Daidzeína & $5,33 \pm 0,02$ \\
Gliciteína & $6,05 \pm 0,21$ \\
Genisteína & $3,80 \pm 0,04$ \\
Totais & $305,40 \pm 1,56$ \\
\hline
\end{tabular}

Média \pm desvio padrão.

As isoflavonas da soja podem sofrer transformações durante o processamento de alguns alimentos. As formas esterificadas podem sofrer conversão para formas glicosiladas e agliconas. Essa conversão ocorre sob aquecimento, quando as formas malonil gliosídeos passam para acetil glicosídeos e também as enzimas naturalmente presentes na soja hidrolisam $\beta$-glicosídeos e liberam glicose e agliconas (LUI et al., 2003).

Comparando os resultados de isoflavonas totais $(305,40 \mathrm{mg} / 100 \mathrm{~g}) \mathrm{com}$ os encontrados por Ciabotti et al. (2006), que analisaram o nível de isoflavonas em soja comum (SC), soja comum branqueada (SCB) e soja livre de lipoxigenase (SLL), encontraram os seguintes resultados de isoflavonas totais: SC 174,51 $\mathrm{mg} / 100 \mathrm{~g}$, SCB $145,97 \mathrm{mg} / 100 \mathrm{~g}$ e SLL 220,21 mg/100 g, sendo quantidades inferiores às isoflavonas totais quantificadas neste trabalho.

O rendimento do ES (Tabela 1.4) foi maior com o aumento da concentração de água utilizada na obtenção, tanto para as amostras centrifugadas quanto para as não centrifugadas. No rendimento do okara, ocorreu o contrário: aumentou com a diminuição da concentração de água na obtenção. Pode-se destacar que o rendimento de ES das amostras 1:8C e 1:8SC foram iguais (65 g/100 g) e também das amostras 1:6C e 1:6SC (61 g/100 g), porém, seus respectivos resíduos de okara não foram iguais. 
Tabela 1.4 Rendimento dos produtos obtidos (\%)

\begin{tabular}{ccc}
\hline Amostras & Extrato de soja & Okara \\
\hline $1: 10 C^{*}$ & 72,72 & 4,94 \\
$1: 8 C$ & 65,92 & 7,83 \\
$1: 6 C$ & 61,90 & 10,15 \\
$1: 4 C$ & 33,33 & 18,26 \\
$1: 10 S C^{*}$ & 66,65 & 6,54 \\
$1: 8 S C$ & 65,83 & 8,50 \\
$1: 6 S C$ & 61,11 & 12,55 \\
$1: 4 S C$ & 41,66 & 20,56 \\
\hline
\end{tabular}

${ }^{*} \mathrm{C}=$ centrifugado e $\mathrm{SC}=$ sem centrifugação.

Larosa et al. (2006) afirmam que $1 \mathrm{~kg}$ de grãos de soja rende de 6 a 9 litros de extrato de soja; em porcentagem, esses valores seriam de $54 \%$ a $81 \%$ de extrato de soja. Apenas os rendimentos das amostras 1:4 com e sem centrifugação ficaram abaixo do rendimento estimado por esse autor. Já para o okara, segundo Bowles e Demiate (2006), com $1 \mathrm{~kg}$ de grãos de soja pode ser obtido aproximadamente $1,1 \mathrm{~kg}$ de okara úmido que, com a desidratação, gera $250 \mathrm{~g}$ de okara seco; em porcentagem, o rendimento do okara úmido seria de aproximadamente $10 \%$. Se comparado a esse trabalho, o resultado obtido para a amostra 1:6C foi semelhante; valores bem maiores foram obtidos neste trabalho para as menores diluições (1:4C, 18,26\% e 1:4SC, 20,56\%). Com isso, se pode afirmar que, se o objetivo é ter maior aproveitamento de ES, deve-se utilizar maior proporção de água; e o contrário, utilizar menor quantidade de água para se obter maior porcentagem de okara.

$\mathrm{Na}$ composição proximal do ES (Tabela 1.5), em relação à umidade, pode-se observar que somente a amostra 1:4C diferiu estatisticamente entre as amostras centrifugadas. Os maiores teores de proteínas foram encontrados nas amostras com diluição 1:4, independentemente do uso da centrifugação. A proteína é um importante componente da soja, e pode ser mais bem aproveitada quando se obtém ES com menor quantidade de água.

A proporção de água utilizada na obtenção do extrato influenciou no conteúdo de cinzas das amostras. Os extratos da diluição 1:4 com e sem centrifugação apresentaram os maiores teores de cinzas: $1,43 \mathrm{~g} / 100 \mathrm{~g}$ e $1,17 \mathrm{~g} / 100 \mathrm{~g}$, respectivamente, havendo diferença significativa quando comparados a todas as outras diluições, sugerindo que o conteúdo de minerais será maior se for utilizada menor quantidade de água no processamento. A porcentagem de lipídios das amostras $1: 10$ SC $(1,17)$ e $1: 8$ SC $(1,17)$ foram iguais estatisticamente e diferentes de todas 
as outras amostras. Nos valores de carboidratos, pode-se observar que o extrato de soja tem pouco desse nutriente em sua composição.

Tabela 1.5 Composição proximal do extrato de soja $(\mathrm{g} / 100 \mathrm{~g})$

\begin{tabular}{cccccc}
\hline ES* $^{*}$ Umidade & Proteinas & Cinzas & Lipidios & Carboidratos $^{* *}$ \\
\hline $1: 10 C^{*}$ & $96,04 \pm 0,42^{a}$ & $1,76 \pm 0,31^{b}$ & $0,28 \pm 0,03^{\text {cdef }}$ & $2,25 \pm 0,09^{a}$ & $-0,33$ \\
$1: 8 C$ & $95,46 \pm 0,42^{a}$ & $2,08 \pm 0.13^{b}$ & $0,37 \pm 0,03^{b f}$ & $2,48 \pm 0,35^{a}$ & $-0,39$ \\
$1: 6 C$ & $95,62 \pm 0,45^{a}$ & $1,73 \pm 0,29 b$ & $0,40 \pm 0,01^{\text {bd }}$ & $2,55 \pm 0,52^{a}$ & $-0,30$ \\
$1: 4 C$ & $88,16 \pm 5,51^{\text {bcd }}$ & $3,75 \pm 1,02^{a}$ & $1,43 \pm 0,11^{a}$ & $2,12 \pm 0,13^{a}$ & 4,45 \\
$1: 10 S C^{*}$ & $95,93 \pm 0,58^{a}$ & $2,42 \pm 0,43^{b}$ & $0,39 \pm 0,04^{\text {be }}$ & $1,17 \pm 0,04^{b}$ & 0,09 \\
$1: 8 S C$ & $93,82 \pm 0,89^{a b}$ & $2,31 \pm 0,19^{b}$ & $0,50 \pm 0,07^{b c}$ & $1,40 \pm 0,16^{b}$ & 1,97 \\
$1: 6 S C$ & $92,3 \pm 0,45^{a c}$ & $2,80 \pm 0,14^{a b}$ & $0,65 \pm 0,07^{b}$ & $2,17 \pm 0,04^{a}$ & 2,08 \\
$1: 4 S C$ & $90,71 \pm 0,04^{a d}$ & $3,77 \pm 0,33^{a}$ & $1,17 \pm 0,28^{a}$ & $2,44 \pm 0,12^{a}$ & 1,91 \\
\hline
\end{tabular}

Média \pm desvio padrão. Médias seguidas pela mesma letra na mesma coluna não apresentam diferença significativa pelo Teste de Tukey $(p \leq 0,05)$. ${ }^{*} E S=$ extrato de soja; $C=$ centrifugado e $S C=$ sem centrifugação.

* *Carboidratos foram calculados por diferença.

Comparando os resultados obtidos no presente estudo com Caus et al. (2008), que obtiveram 1,19 g/100 g de cinzas, 88,48 g/100 g de umidade, 1,76 $\mathrm{g} / 100 \mathrm{~g}$ de proteínas e $1,95 \mathrm{~g} / 100 \mathrm{~g}$ de lipídios, notou-se que os percentuais de cinzas e de umidade das amostras 14:C e 1:4SC foram semelhantes. Já para proteínas, as amostras 1:10C e 1:6C obtiveram resultados parecidos, e para lipídios, as amostras 1:4C e 1:6SC tiveram valores próximos. Essas diferenças podem ter ocorrido pelos diferentes métodos de extração, pela solubilidade desses compostos e/ou pelas diferentes variedades de soja.

Com a determinação da composição proximal do okara (Tabela 1.6), pode-se observar que o uso da centrifugação e as diferentes quantidades de água usadas na obtenção do okara influenciaram nos teores de umidade, proteínas e lipídios. No entanto, os teores de cinzas foram iguais estatisticamente para todas as amostras. A umidade foi a mais influenciada com o uso dos diferentes métodos de obtenção dos produtos: somente as amostras 1:6SC e 1:4SC não diferiram estatisticamente. Nos percentuais de proteínas e lipídios, foi verificado que o uso da centrifugação não influenciou, já que não foram observadas diferenças estatísticas entre essas amostras.

Ao comparar esses resultados com o obtido por da Cunha et al. (2007), em que a umidade foi de 7,0 g/100 g, apenas a amostra 1:10C apresentou resultado próximo. Bowles e Demiate (2006) caracterizaram o okara e encontraram os seguintes resultados em base seca: cinzas 2,8 g/100 g, proteínas 37,0 g/100 g, 
lipídios $13 \mathrm{~g} / 100 \mathrm{~g}$, resultados inferiores aos encontrados neste trabalho em todas as determinações. Essas diferenças na composição química são comuns, pois o local em que foram cultivadas, o genótipo e as condições climáticas alteram significativamente a composição química da soja e, com isso, alteram também a composição de seus derivados (POYSA; WOODROW, 2001).

Tabela 1.6 Composição proximal do okara, em base seca $(\mathrm{g} / 100 \mathrm{~g})$

\begin{tabular}{cccccc}
\hline Okara & Umidade & Proteínas & Cinzas & Lipídios & Carboidratos \\
\hline $1: 10 C^{*}$ & $6,50 \pm 0,23^{\mathrm{a}}$ & $44,40 \pm 0,24^{\mathrm{c}}$ & $3,25 \pm 0,15^{\mathrm{a}}$ & $23,94 \pm 1,02^{\mathrm{b}}$ & $28,40 \pm 1,14$ \\
$1: 8 C$ & $13,50 \pm 0,01^{\mathrm{e}}$ & $44,44 \pm 3,16^{\mathrm{c}}$ & $3,30 \pm 0,25^{\mathrm{a}}$ & $21,83 \pm 1,09^{\mathrm{b}}$ & $30,44 \pm 3,86$ \\
$1: 6 C$ & $11,08 \pm 0,25^{\mathrm{f}}$ & $43,60 \pm 2,72^{\mathrm{c}}$ & $3,50 \pm 0,22^{\mathrm{a}}$ & $22,85 \pm 044^{\mathrm{b}}$ & $30,04 \pm 3,13$ \\
$1: 4 \mathrm{C}$ & $23,11 \pm 0,73^{\mathrm{c}}$ & $46,63 \pm 0,36^{\mathrm{c}}$ & $4,14 \pm 0,07^{\mathrm{a}}$ & $23,45 \pm 1,36^{\mathrm{b}}$ & $25,78 \pm 1,70$ \\
$1: 1$ SSC $^{*}$ & $29,18 \pm 0,39^{\mathrm{a}}$ & $51,96 \pm 0,71^{\mathrm{ab}}$ & $2,34 \pm 0,03^{\mathrm{a}}$ & $31,62 \pm 1,45^{\mathrm{a}}$ & $14,08 \pm 2,82$ \\
$1: 8 S C$ & $21,56 \pm 0,19^{\mathrm{d}}$ & $47,02 \pm 2,10^{\mathrm{b}}$ & $3,59 \pm 0,05^{\mathrm{a}}$ & $25,31 \pm 2,17^{\mathrm{b}}$ & $24,09 \pm 3,85$ \\
$1: 6 S C$ & $28,06 \pm 0,18^{\mathrm{b}}$ & $52,76 \pm 1,18^{\mathrm{ab}}$ & $3,95 \pm 0,06^{\mathrm{a}}$ & $29,41 \pm 1,92^{\mathrm{a}}$ & $15,20 \pm 2,82$ \\
$1: 4 S C$ & $27,61 \pm 0,14^{\mathrm{b}}$ & $46,20 \pm 0,95^{\mathrm{c}}$ & $4,28 \pm 0,07^{\mathrm{a}}$ & $24,90 \pm 1,35^{\mathrm{b}}$ & $24,62 \pm 2,15$ \\
\hline
\end{tabular}

Média \pm desvio padrão. Médias seguidas pela mesma letra na mesma coluna não apresentam diferença significativa pelo Teste de Tukey $(p \leq 0,05)$. ${ }^{*} \mathrm{C}=$ centrifugado e SC $=$ sem centrifugação.

$\mathrm{Na}$ análise dos sólidos solúveis (Tabela 1.7) pode-se observar que os resultados foram proporcionais à quantidade de água utilizada nas extrações: conforme aumentou a proporção de água, diminuiu a quantidade de sólidos solúveis. Isso ocorreu tanto nas amostras com e sem o uso de centrifugação, e os resultados foram parecidos entre as amostras de mesma diluição. Esse é um fator importante a ser analisado antes da aplicação do extrato de soja em alguma bebida, pois se o objetivo é ter um líquido mais fluido, é melhor utilizar maiores proporções de água; se for obter uma bebida mais espessa, seria interessante utilizar as menores proporções.

Em relação ao teor de isoflavonas, que são um componente funcional muito importante da soja, os valores foram semelhantes aos dos grãos, mostrando que os extratos de soja contêm as mesmas propriedades do grão. Em média, as amostras apresentaram $342,81 \mathrm{mg} / 100 \mathrm{~g}$ de isoflavonas totais. $\mathrm{Na}$ análise de cor dos ES, o parâmetro $a^{*}$ indicou que todos os extratos são esverdeados (valores negativos) e o parâmetro b* indicou que são amarelos (valores positivos). Fatores importantes, pois indica que a proporção de água e a centrifugação não alteraram a cor dos extratos. Pode-se destacar as amostras dos extratos mais concentrados 1:4C e 1:4SC, que apresentaram menor intensidade de verde $(-1,9$ e $-0,1)$ e maior intensidade de cor amarela $(13,2$ e 19,7$)$. 
Tabela 1.7 Sólidos solúveis (\%), isoflavonas $(\mathrm{g} / 100 \mathrm{~g})$ e cor do ES

\begin{tabular}{|c|c|c|c|c|}
\hline \multirow{2}{*}{ Extrato de soja } & \multirow{2}{*}{ Sólidos solúveis } & \multirow{2}{*}{ Isoflavonas } & \multicolumn{2}{|c|}{ Cor } \\
\hline & & & $\mathbf{a}^{*}$ & $\mathbf{b}^{*}$ \\
\hline $1: 10 C^{*}$ & $4,33 \pm 0,38^{e}$ & $393,06 \pm 5,86^{a}$ & $-2,59 \pm 0,08^{b c}$ & $4,74 \pm 0,20^{e}$ \\
\hline $1: 8 \mathrm{C}$ & $5,25 \pm 0,25^{b c}$ & $385,45 \pm 5,87^{a}$ & $-2,59 \pm 0,20^{b c}$ & $7,51 \pm 0,59 d$ \\
\hline $1: 6 C$ & $4,42 \pm 0,38$ cde & $355,16 \pm 11,97 b$ & $-2,20 \pm 0,18^{\mathrm{cd}}$ & $9,20 \pm 0,51^{c}$ \\
\hline $1: 4 C$ & $7,17 \pm 0,29 a$ & $319,66 \pm 14,56^{b}$ & $-1,93 \pm 0,05^{d}$ & $19,66 \pm 0,75^{a}$ \\
\hline $1: 10 S C^{*}$ & $4,25 \pm 0,25^{e}$ & $402,96 \pm 17,57^{a}$ & $-2,63 \pm 0,02^{b c}$ & $5,53 \pm 0,12^{e}$ \\
\hline $1: 8 S C$ & $5,25 \pm 0,43^{b d}$ & $317,34 \pm 13,14$ & $-3,08 \pm 0,24^{a}$ & $5,54 \pm 0,60$ \\
\hline $1: 6 S C$ & $6,08 \pm 0,14^{b}$ & $302,44 \pm 13,75^{\circ}$ & $-2,80 \pm 0,14^{a b}$ & $6,35 \pm 0,76^{\mathrm{de}}$ \\
\hline $1: 4 S C$ & $7,77 \pm 0,23^{a}$ & $266,44 \pm 1,93^{d}$ & $-0,10 \pm 0,17 \mathrm{e}$ & $13,20 \pm 0,58^{b}$ \\
\hline
\end{tabular}

Média \pm desvio padrão. Médias seguidas pela mesma letra na mesma coluna não apresentam diferença significativa pelo Teste de Tukey $(p \leq 0,05)$. ${ }^{*} C=$ centrifugado e $S C=$ sem centrifugação.

Seibel et al. (2013) obtiveram extratos de soja de diferentes variedades da Embrapa Soja na proporção de 1:6 (grão:água), realizaram análise de sólidos solúveis desses extratos e obtiveram como resultados valores que variaram entre $6,29 \%$ para a variedade BRS 258 e $11,00 \%$ para a BRS 232. Resultados semelhantes a este trabalho foram para as variedades Embrapa 48 (7,84\%), BRS 213 $(7,65 \%)$ e para a BRS $216(7,03 \%)$, comparando com a proporção de 1:4 com e sem centrifugação.

Os mesmo autores também realizaram a análise de isoflavonas dos extratos de soja, e, para a mesma variedade de soja deste trabalho, o valor foi de 380,44 $\mathrm{mg} / 100 \mathrm{~g}$ no total desse composto. Valor parecido foi obtido para o extrato na proporção de $1: 8 \mathrm{C}$, que foi de $385,45 \mathrm{mg} / 100 \mathrm{~g}$. Nas outras proporções, foi possível obter valores maiores de isoflavonas, como nas proporções 10:SC e 1:10C, que não diferiram da 1:8C.

Para a análise de cor, comparando os resultados com os de Poliseli-Scopel et al. (2013), que analisaram a cor do extrato de soja homogeneizado por ultra alta temperatura a $200 \mathrm{Mpa}$ e a $75{ }^{\circ} \mathrm{C}$ e avaliados em dias diferentes, os resultados obtidos foram semelhantes com os deste trabalho nos dias 1, 7, 14, 21 e 28. Para os valores de $\mathrm{a}^{*}$, que foram de $-2,68 \mathrm{e}-3,11$, e para $\mathrm{b}^{*}$ os autores obtiveram valores de 9,17 e 9,65, que foram semelhantes apenas para a amostra 1:6C $(9,20)$.

O okara possui boa capacidade de hidratação, comprovada pelos resultados de volume de intumescimento e índice de absorção de água (Tabela 1.8), destacando a amostra 1:8C que apresentou o maior valor de VI (volume de intumescimento). Dentre os valores de VI das amostras sem centrifugação, todos foram iguais estatisticamente. O IAA não foi afetado pelos diferentes métodos de ob- 
tenção do okara: todas as amostras não apresentaram diferença estatística, sendo importante mencionar que esse índice foi maior no okara do que no grão da soja, o que pode favorecer o uso desse ingrediente em alimentos.

Tabela 1.8 Propriedades tecnológicas do okara

\begin{tabular}{|c|c|c|c|c|}
\hline Okara & VI $(\mathrm{ml} / \mathrm{g})^{*}$ & IAA $(g / g)^{*}$ & IAO $(\mathrm{g} / \mathrm{g})^{*}$ & Densidade $(\mathrm{g} / \mathrm{ml})$ \\
\hline $1: 10 C^{*}$ & $7,33 \pm 0,0,58^{c d}$ & $4,75 \pm 0,11^{a}$ & $2,75 \pm 0,12^{\mathrm{bcd}}$ & $0,43 \pm 0,04^{\text {ac }}$ \\
\hline $1: 8 \mathrm{C}$ & $10,17 \pm 0,29 a$ & $5,37 \pm 0,05^{a}$ & $3,19 \pm 0,14^{\mathrm{ab}}$ & $0,35 \pm 0,02^{\mathrm{e}}$ \\
\hline $1: 6 C$ & $9,33 \pm 0,58^{\mathrm{ac}}$ & $4,97 \pm 0,08^{a}$ & $3,14 \pm 0,25^{\mathrm{ac}}$ & $0,34 \pm 0,03^{e}$ \\
\hline $1: 4 C$ & $9,67 \pm 0,58^{\mathrm{ab}}$ & $4,88 \pm 0,18^{a}$ & $2,74 \pm 0,03^{\mathrm{bcd}}$ & $0,39 \pm 0,01^{b c d}$ \\
\hline $1: 10 \mathrm{SC}^{*}$ & $8,00 \pm 1,00^{\mathrm{bcd}}$ & $6,41 \pm 0,45^{a}$ & $3,45 \pm 0,18^{a}$ & $0,437 \pm 0,01^{a c}$ \\
\hline $1: 8 S C$ & $8,33 \pm 0,58^{\mathrm{ad}}$ & $6,65 \pm 0,29^{a}$ & $3,20 \pm, 0,21^{a b}$ & $0,470 \pm 0,01^{a}$ \\
\hline $1: 6 S C$ & $8,33 \pm 0,58^{\mathrm{ad}}$ & $7,22 \pm 4,3^{a}$ & $3,10 \pm 0,05^{\mathrm{ad}}$ & $0,423 \pm 0,01$ \\
\hline $1: 4 S C$ & $7,33 \pm 1,15^{\mathrm{cd}}$ & $5,78 \pm 0,19^{a}$ & $3,83 \pm 0,75^{a}$ & $0,445 \pm 0,2^{a b}$ \\
\hline
\end{tabular}

Média \pm desvio padrão. Médias seguidas pela mesma letra na mesma coluna não apresentam diferença significativa pelo Teste de Tukey $(p \leq 0,05)$. ${ }^{*} \mathrm{C}=$ centrifugado; $\mathrm{SC}=$ sem centrifugação; $\mathrm{VI}=$ volume de intumescimento; $I A A$ = índice de absorção de água; $I A O=$ índice de absorção de óleo.

Em relação ao índice de absorção de óleo, analisando todos os valores de maneira geral, foi menor que os valores de IAA. Com isso, pode-se observar que o okara interage melhor com a água. Os valores de IAA e IAO deste trabalho foram superiores aos encontrados por Seibel e Beléia (2009), os quais foram índice de absorção de água (IAA) 3,8 g/g e índice de absorção de óleo (IAO) 2,4 g/g para uma farinha desengordurada de soja e semelhante para o volume de intumescimento (VI) $8,7 \mathrm{ml} / \mathrm{g}$. Os valores de densidade foram significativamente superiores nas amostras sem o uso de centrifugação; apenas a amostra 1:10C apresentou valor igual às amostras sem centrifugação.

Pode-se afirmar que o rendimento dos extratos e okaras foram influenciados pela concentração de água e pelo uso da centrifugação, assim como a composição química e as propriedades tecnológicas dos produtos, sendo interessante alterar a proporção de água e usar ou não a força centrífuga para a separação do extrato de soja e do okara, dependendo do alimento em que for aplicado. A quantidade de proteína, que é um dos componentes mais importantes, foi maior no extrato quando esse não foi centrifugado; para o okara, essa pode ser mais bem extraída quando não for utilizada a centrifugação; as isoflavonas foram maiores nas amostras de maior diluição de água (1:0 C, 1:8C e 1:10SC). 


\section{CONCLUSÃO}

O extrato de soja é muito utilizado na preparação de sucos e bebidas à base de soja, por isso é muito importante saber em qual diluição pode-se obter as melhores características para incorporar mais nutrientes no alimento em que for aplicado. Considerado como um resíduo da produção do ES, o okara ainda não é utilizado por indústrias alimentícias. Com este trabalho, pôde-se observar que o okara possui um grande potencial para aplicação em alimentos, pois suas determinações químicas e tecnológicas obtiveram resultados semelhantes ao do grão de soja, como alto teor de proteínas, baixo teor de lipídios e boa capacidade de hidratação. O okara apresentou inclusive valores de índice de absorção de água superiores aos do grão de soja. Por conseguinte, essa propriedade, de absorver mais água, pode ajudar a aumentar o rendimento de massas e biscoitos, por exemplo.

Pode-se concluir que é possível obter extrato de soja e okara por diferentes métodos, resultando em produtos distintos, cujo rendimento foi alterado pela aplicação da força centrífuga. Quimicamente, pode-se observar variação na composição proximal dos extratos e okara nas diferentes proporções de água utilizadas; ademais, pode-se destacar as amostras de extrato de soja sem o uso da centrifugação que apresentaram altos valores de proteínas, e o okara, o qual apresentou a composição química semelhante à do grão de soja. Cumpre ressaltar por fim que também houve diferenças nas propriedades tecnológicas.

\section{REFERÊNCIAS}

APLEVICZ, K.; DEMIATE, I. M. Análises físico-químicas de pré-misturas de pães de queijo e produção de pães de queijo com adição de okara. Ciênc. Agrotec., Lavras, v. 31, n. 5, p. 1416-1422, set./out. 2007.

ASSOCIATION OF ANALYTICAL COMMUNITIES. Official methods of analysis. 16. ed. Arlington: AOAC International, 1995. v. 1-2.

BARBOSA, E. G. Prevalência de bactéria probiótica L. acidophilus - NCFM em extrato de soja fermentado e saborizado com sacarose e polpa de pêssego. Dissertação (Mestrado) - Programa de Pós-Graduação em Ciência e Tecnologia Agroindustrial, Universidade Federal de Pelotas. Rio Grande do Sul, 2007. 73 f.

BEHRENS, J. H.; DA SILVA, M. A. A. P. Atitude do consumidor em relação à soja e produtos derivados. Ciênc. Tecnol. Aliment., Campinas, set. 2004.

BERHOW, M. A. Modern analytical techniques for flavonoid determination. In: BUSLIG, B. S.; ANTHEY, J. A. (Eds.). Flavonoids in the living cell. New York: Kluwer Academic, 2002. p. 61-76.

BOWLES, S.; DEMIATE, I. M. Caracterização físico-química de okara e aplicação em pães do tipo francês. Ciênc. Tecnol. Aliment., Campinas, v. 26, n. 3, jul./set. 2006. 
BRANCO, I. G. et al. Avaliação da aceitabilidade sensorial de uma bebida à base de extrato hidrossolúvel de soja, polpa de morango e sacarose. Revista Ciências Exatas e Naturais. jan./jun. 2007.

CALLOU, K. R. A. Teor de isoflavonas e capacidade antioxidante de bebidas à base de soja. Dissertação (Mestrado) - Programa de Pós-graduação em Ciências dos Alimentos, Universidade de São Paulo. São Paulo, 2009. 130 f.

CANTUÁRIA, C. M. et al. Perfil sensorial de pães de forma enriquecidos com okara. Revista Brasileira de Produtos Agroindustriais, Campina Grande, v. 10, 2008.

CARRÃO-PANIZZI, M. C.; FAVONI, S. P. G.; KIKUCHI, A. Extraction time for isoflavone determination. Brazilian Archives of Biology and Technology, Curitiba, v. 45, n. 4, p. 515-518, dez. 2002.

CASÉ, F. et al. Produção de 'leite' de soja enriquecido com cálcio. Ciênc. Tecnol. Aliment., Campinas, mar. 2005.

CAUS, S. et al. Obtenção de bebidas à base de extrato hidrossolúvel de soja com polpa de frutas. Revista Ciências Exatas e Naturais, v. 10, n. 1, jan./jun. 2008.

CIABOTTI, S. et al. Avaliações químicas e bioquímicas dos grãos, extratos e tofus de soja comum e de soja livre de lipoxigenase. Ciênc. agrotec., Lavras, v. 30, n. 5, p. 920 929, set./out. 2006.

DA CUNHA, M. A. A. et al. Produção de biscoitos com subproduto de soja (okara). Synergismus scyentifica UTFPR, Pato Branco, v. 2, p. 1-4, 2007.

DANELUZ, D.; DA CUNHA, M. A. A. Produção de biscoitos formulados com farinhas de berinjela (solanum melongena, 1.) e okara. In: XIV SICITE-UTFPR. Volume I - Seção Alimentos, 2009.

DOS SANTOS, C. G. P.; MIGUEL, D. P.; LOBATO, F. M. Processamento de "hambúrgueres" à base de resíduo de soja "okara": análise físico-química, sensorial e microbiológica. In: IX Jornada Científica da FAZU, Uberaba, 2010.

FANTE, C. A. et al. Isoflavone and protein content in soybeans grains submitted to flooding at different stages of development. Ciência Rural, v. 41, n. 12, dez. 2011. HIRAKURI, M. H.; LAZZAROTTO, J. J. Evolução e Perspectivas de Desempenho Econômico Associadas com a Produção de Soja nos Contextos Mundial e Brasileiro. Documentos 319. Londrina: Emprapa Soja, 2010.

INSTITUTO ADOLFO LUTZ. Normas analíticas do Instituto Adolfo Lutz: métodos químicos e físicos para análise de alimentos. 4. ed. São Paulo: Imesp, 2008.

JÚNIOR, M. S. S. et al. Otimização da formulação de pães de forma preparados com diferentes proporções de farinha de trigo, fécula de mandioca e okara. B. CEPPA, Curitiba, v. 24, n. 1, p. 221-248, jan./jun. 2006.

KEMPKA, A. P. et al. Formulação de bebida láctea fermentada sabor pêssego utilizando substratos alternativos e cultura probiótica. Ciênc. Tecnol. Aliment., Campinas, v. 28(supl.), p. 170-177, dez. 2008. 
LAROSA, G. et al. Aspectos sensoriais, nutricionais e tecnológicos de biscoito doce contendo farinha de 'okara'. Alim. Nutr., Araraquara, v. 17, n. 2, p. 151-157, abr./jun. 2006.

LUI, M. C. Y. et al. Isoflavonas em isolados e concentrados protéicos de soja. Ciênc. Tecnol., Campinas, v. 23(supl.), p. 206-212, dez. 2003.

MADRONA, G. S.; ALMEIDA, A. M. Elaboração de biscoitos tipo cookie à base de okara e aveia. Revista Tecnológica, v. 17, p. 61-72, 2008.

MAIA, M. J. L.; ROSSI, E. A.; DE CARVALHO, M. R. B. Qualidade e rendimento do "leite" de soja da unidade de produção de derivados da soja UNISOJA - FCF - Ar/ UNESP. Alim. Nutr., Araraquara, v. 17, n. 1, p. 65-72, jan./mar. 2006.

MANDARINO, J. M. G.; BENASSI, V. DE T.; CARRÃO-PANIZZI, M. C. Manual de receitas com Soja. Documentos 206. Londrina: Embrapa Soja, 2003.

MOREIRA, R. W. M. et al. Avaliação sensorial e reológica de uma bebida achocolatada elaborada a partir do extrato hidrossolúvel de soja e soro de queijo. Acta Scientiarum. Technology, Maringá, v. 32, n. 4, p. 435-438, 2010.

PEREIRA, M. O. et al. Elaboração de uma bebida probiótica fermentada a partir de extrato hidrossolúvel de soja com sabor de frutas. Ambiência - Revista do Setor de Ciências Agrárias e Ambientais, v. 5, n. 3, set./dez. 2009.

PERUSSELLO, C. A. Estudo dos parâmetros de processo e modelagem numérica da secagem do resíduo sólido da produção do extrato hidrossolúvel de soja (okara). Curitiba: Biblioteca PUCPR, 2008.

POLISELI-SCOPEL, F. H. et al. Characteristics of soymilk pasteurized by ultra high pressure homogenization (UHPH). Innovative Food Science and Emerging Technologies, v. 22, p. 73-80, 2013.

POYSA, V.; WOODROW, L. Stability of soybean seed composition and its effect on soymilk and tofu yield and quality. Food Research International, v. 35, p. 337-345, 2001. SEIBEL, N. F.; BELÉIA, A. D. P. Características químicas e funcionalidade tecnológica de ingredientes de soja [Glycine Max (L.) Merrill]: carboidratos e proteínas. Braz. J. Food Technol., v. 12, n. 2, p. 113-122, abr./jun. 2009.

SEIBEL, N. F. et al. Brazilian soybean varieties for human use. In: EL-SHEMY H. A. Soybean - bio-active compounds. Disponível em: <http://cdn.intechopen.com/pdfs/39505/ InTech-Brazilian_soybean_varieties_for_human_use.pdf> Acesso em: 15 ago. 2013.

STATISTICA. Version 10 [data analysis software system]: STATSOFT, INC., 2011.

TASHIMA, E. H.; CARDELLO, H. M. A. B. Perfil sensorial de extrato de hidrossolúvel de soja (Glicine Max L. Merril) comercial adoçada com sacarose e com sucralose. B. CEPPA, Curitiba, v. 21, n. 2, p. 409-428, jul./dez. 2003.

ULIANA, M. R.; FILHO, W. G. V. Análise energética de bebida mista de extrato hidrossolúvel de soja e suco de amora. Revista Energia na Agricultura, Botucatu, v. 25, n. 3, p. 94-103, 2010.

ZADINELLO, R. E. et al. Métodos de extração, formulação e avaliação sensorial de produto à base de extrato hidrossolúvel de soja. Revista Varia Scientia Agrárias, v. 1, n. 1, p. 111-120, 2010. 
